\title{
DESIGUALDADE SALARIAL ENTRE GÊNEROS
}

WAGE INEQUALITY BETWEEN GENDERS

Natalia Silva MILAN ${ }^{1}$

ISSUE DOI: $10.21207 / 2675-0104.2017 .682$

\section{RESUMO}

A luta das mulheres para o ingresso no mercado de trabalho foi árdua, após tal inserção passaram a assumir funções importantes dos setores econômicos, contudo tal ingresso tem sido acompanhado de segregações e discriminações que as colocam em condições menos favoráveis no campo socioprofissional. Diante disso um dos desafios desse século é a busca por igualdade salarial da mulher em relação aos homens, com o mesmo nível de escolaridade e função exercida. Dessa forma, será discutido desde os primeiros direitos conquistados, evidenciar historicamente o grande avanço conquistado no mercado de trabalho até os empecilhos e causas ainda existentes nos dias atuais, igualmente demonstrar possíveis caminhos para efetivar o direito da igualdade feminina. Ainda, analisar a morosidade do projeto de lei que visa acrescentar multa para o empregador e sua eventual eficácia. O tema escolhido tem como objetivo demonstrar a importância da paridade, trazer um olhar que contribua para uma nova concepção e ruptura com ideais patriarcais.

Palavras-chave: Mulher, Mercado De Trabalho, Igualdade Salarial, Discriminação.

\section{ABSTRACT}

The struggle of women to enter the labor market was arduous, after such insertion began to assume important functions of the economic sectors, however such entry has been accompanied by segregation and discrimination that put them in less favorable conditions in the socio-professional field. In view of this one of the challenges of this century is the search for equal wages of women in relation to men, with the same level of education and function. Thus, this research aims to cover from the earliest conquered rights, to evidence historically the great advance achieved in the labor market to the obstacles and causes still existing in the present day, also to demonstrate possible ways to effect the right of

\footnotetext{
${ }^{1}$ Discente da Faculdade de Direito de Franca (FDF) Franca/SP. Bolsista do Programa Interno de Iniciação Cientítica (PIBIC 2016-2017
} 
feminine equality. Also, analyze the slowness of the bill that aims to add a fine to the employer and its possible effectiveness. The chosen theme aims to demonstrate the importance of parity, to bring a look that contributes to a new conception and rupture with patriarchal ideals.

Keywords: Women, Labor Market, Wage Equality, Discrimination.

\section{INTRODUÇÃO}

A desigualdade salarial entre gêneros é uma discriminação ainda muito presente na coletividade atual, dessa forma é necessário evidenciar as vitórias e aquisições das mulheres trazidas pelo Ordenamento Jurídico para que por consequência seja analisadas possíveis medidas a serem dotadas pela legislação a fim de intimidar e penalizar o empregador que insiste em não respeitar o princípio constitucional da igualdade.

A sociedade brasileira foi constituída com ideais patriarcais, e isso fez com que a admissão mulher no mercado de trabalho fosse morosa, resultando para elas o trabalho de cuidar do lar e da família. Com o advento da Revolução Industrial, o crescimento do mercado de trabalho e a necessidade de rendimento familiar ocasionaram na absorção da mulher no mercado de trabalho, porém de forma restrita, apenas em alguns seguimentos e como uma mão de obra barata.

Conforme o Artigo 13, inciso I da Constituição Federal, "todos são iguais perante a lei”, porém não é o que ocorre a prática e as mulheres vêm tentando trazer para uma realidade fática nos dias atuais, após vários anos do advento da atual Constituição. A diferença salarial é verificada em todas as áreas de atuação e principalmente em grandes seguimentos do nosso país, o mesmo cargo, função e diversos salários em relação aos gêneros.

Ainda existem diversos desafios e causas da diferenciação de remuneração, na sua grande maioria própria da biologia feminina, tal como maternidade, amamentação e cuidados com os filhos. Importante ressaltar de igual forma à necessidade de afastar as circunstâncias protetivas que não dizerem respeito a condições intrínsecas ao sexo feminino e influenciam diretamente em um salário menor.

\section{EVOLUÇÃO HISTÓRICA DO TRABALHO HUMANO E ASPECTOS LEGAIS}


Nos dias que correm o trabalho é tratado como algo natural e procurado pela maior parcela da população como forma de garantir o sustento próprio, o da família e ainda como importante forma de ascensão profissional e até mesmo pessoal. Da forma pelo qual o labor é considerado, oculta um lado sombrio, a escravidão, forma de trabalho utilizada no país de 1530 -1888 .

Sob a perspectiva de Cassar:

Do ponto de vista histórico e etimológico a palavra trabalho decorre de algo desagradável: dor, castigo, sofrimento, tortura. O termo trabalho tem origem no latim - tripalium. Espécie de instrumento de tortura ou canga que pesava sobre os animais. Por isso, os nobres, os senhores feudais ou os vencedores não trabalhavam, pois consideravam o trabalho uma espécie de castigo. ${ }^{2}$

A colonização e a vinda dos portugueses ao Brasil conduziram consigo a contar do século XVII o modo de produção escravista. O transporte dos negros era precário, trazidos nos porões dos navios negreiros, acorrentados, amontoados, em condições subumanas para serem vendidos para os fazendeiros no país e até mesmo muitas vezes não chegavam ao destino com vida.

Segundo Sérgio Pinto Martins:

"Os escravos faziam o trabalho duro, enquanto os outros poderiam ser livres. O trabalho não tinha o significado de realização pessoal. As necessidades da vida tinham características servis, sendo que os escravos é que deveriam desempenhá-las [...]. "3

Esquecido na história brasileira as mulheres afrodescendentes também foram exploradas em tal época, submetidas a realização de trabalhos domésticos nas casas grandes.

Com o advento da Lei Bill Aberdeen que possibilitava a interceptação de navios escravistas com destino ao Brasil, o país com as pressões sofridas pela Inglaterra cedeu às intimidações e sancionou a Lei Eusébio de Queiróz pondo fim ao tráfico negreiro. Historicamente tão somente com

\footnotetext{
${ }^{2}$ CASSAR, Vólia Bomfim. Direito Do Trabalho. $3^{\text {a }}$. ed. Niterói: Impetus, 2009, p 3.

${ }^{3}$ MARTINS, Sérgio Pinto. Direito Do Trabalho. 28 ${ }^{\text {a }}$. ed. São Paulo: Atlas, 2012, p. 4.
} 
a referida lei não cessou totalmente o modo de exploração, assim a escravidão realmente terminou no Brasil verdadeiramente com a promulgação da Lei Áurea em 13 de maio de 1888 pela Princesa Isabel,

Finda a escravidão manifestou-se o aparecimento das corporações de ofício, uma grande aliança de trabalhadores do mesmo ramo, surgida na Idade Média. A estrutura atendeu com as necessidades da época, regulamentando as atividades e evitando conflitos, havia uma hierarquia, dividiam-se em mestres, oficiais ou companheiros e aprendizes.

Sérgio Pinto Martins, sobre a segmentação de funções leciona:

Os mestres eram os proprietários das oficinas, que já tinham passado pela prova da obra-mestra. Os companheiros eram trabalhadores que percebiam salários dos mestres. Os aprendizes eram os menores que recebiam dos mestres o ensino metódico do ofício ou profissão $[\ldots] .^{4}$

O declínio das corporações de ofício ocorreu por diversos fatores entre eles a Lei Chapelier, que em seu artigo $1^{\circ}$ estabeleceu o fim da normatização dos trabalhadores e a liberdade de contratar, pois tal modo de produção era atentatório a dignidade do homem e do cidadão.

Demostrando uma parcela das razões do fim das corporações de ofício:

Segundo Eulália Lobo, entre os fatores que concorreram para o declínio ainda podemos encontrar a atividade artesanal desenvolvida em casas particulares (muitas vezes de forma ilegal) por escravos, quebras dos padrões de qualidade dos artigos produzidos e de controle de preços e a utilização de escravos como aprendizes e mesmo oficiais. $^{5}$

Revoluções buscam de um modo geral uma mudança, uma transformação na sociedade, no caso não seria diferente. Os descontentamentos da época respectivamente Revolução Francesa e Industrial, desencadearam tais revoltas, com grandes repercussões no direito.

\footnotetext{
${ }^{4}$ MARTINS, Sérgio Pinto. Direito Do Trabalho. 28a . ed. São Paulo: Atlas, 2012, p. 4.

${ }^{5}$ NASCIMENTO, Amauri Mascaro; FERRARI, Irany; FILHO, Ives Gandra da Silva Martins. História Do Trabalho, Do Direito Do Trabalho E Da Justiça Do Trabalho. $3^{\mathrm{a}}$. ed. São Paulo: LTR, 2011, p.37.

${ }^{5}$ SZMRECSÁNYI, Tamás; Lapa, José Roberto do Amaral. História Econômica Da Independência E Do Império. 2a. Ed. Revista. São Paulo: Hucitec.2002, p.285.
} 
Na Revolução Francesa, o mais expressivo acontecimento jurídico ocorreu em 1789 sendo a Declaração dos Direitos do Homem e do Cidadão, que resultou progressos em aspectos sociais, liberdade de pensamento, amplo crescimento da participação do povo na política e principalmente igualdade de direitos, influenciando a primeira Constituição brasileira, em 1824.

As conquistas da Declaração dos Direitos do Homem e do Cidadão, são considerados direitos humanos de primeira geração, explicando sobre:

os direitos da primeira geração ou direitos da liberdade têm por titular o indivíduo, são oponíveis ao Estado, traduzem-se como faculdades ou atributos da pessoa e ostentam uma subjetividade que é seu traço mais característico; enfim, são direitos de resistência ou de oposição perante o Estado $^{6}$

Mais tardar, o decreto D' Allarde em 1791 na França estabeleceu a liberdade contratual, de comércio e indústria, considerando toda pessoa livre para exercer qualquer profissão que desejasse, mediante pagamento de uma taxa para o Estado e recebimento da patente.

Já com a Revolução Industrial a busca por lucro da burguesia ascendente e os investimentos em tecnologia resultou na máquina a vapor, que possibilitou o avanço da economia e diminuição dos custos, no entanto houve uma enorme desvalorização do trabalho, cada qual fazendo uma pequena parte específica da produção retratada por Charles Chaplin em Tempos Modernos.

\footnotetext{
Afirma-se que o Direito do Trabalho e o contrato de trabalho passaram a desenvolver- se com o surgimento da Revolução Industrial. Constata-se, nessa época, que a principal causa econômica do surgimento da Revolução Industrial foi o aparecimento da máquina a vapor como fonte energética. ${ }^{7}$
}

A atividade econômica após as referidas revoluções foi substituída por máquinas, deixando a força muscular de ser um atributo utilizado na grande parte dos trabalhos da época. Assim, a modernização mais a junção com os salários insuficientes para o sustento familiar possibilizaram o

\footnotetext{
${ }^{6}$ MARTINS, Sérgio Pinto. Direito do trabalho. $28^{a}$. ed. São Paulo: Atlas, 2012, p. 7.

${ }^{7}$ MARTINS, Sérgio Pinto. Direito Do Trabalho. $28^{\text {a }}$. ed. São Paulo: Atlas, 2012, p. 6.
} 
surgimento do trabalho feminino, no entanto se para homens os salários eram escassos para as mulheres eram praticamente medíocres remunerações.

Cronologicamente após, outro acontecimento que abriram as portas para o trabalho feminino foram as guerras mundiais, em razão da ida dos maridos para as guerrilhas foi indispensável para a mulher apoderar-se do trabalho fora de casa com a finalidade garantir o ganha-pão da morada. O que em princípio era algo provisório tornou-se permanente com a morte de uma grande parcela de soldados e com a incapacidade de uma parte dos sobreviventes.

Em matéria civil, conforme previsto no Código de 1916, a mulher casada era considerada perante a sociedade como relativamente incapaz, de tal forma os atos da vida civil apenas eram válidos se assistidos por seu representante legal, no caso o marido.

A incapacidade relativa permite que o incapaz pratique atos da vida civil, desde que assistido por seu represente legal, sob pena de anulabilidade (CC, art. 171, I). ${ }^{8}$

Após uma breve noção histórica dos direitos e sua evolução, é árduo acreditar que até esse tempo ainda existem diferenças salariais entre sexos, tornando a mulher pelo simples fato de ter nascido mulher, um ser humano inferior ao homem. Outrossim, percebe-se que tal preconceito envolve inúmeras dificuldade da mulher se desenvolver profissionalmente e por conta disso a maioria de líderes ainda são homens.

A inoportunidade anterior da mulher no mercado de trabalho e as enormes dificuldades de manter-se no meio resultaram no aceitamento das condições onde eram sujeitas a exaustivas jornadas de trabalho e acabavam por receber salários extremamente inferiores pelo receio de serem excluídas novamente do mercado de trabalho.

Segundo Sérgio Pinto Martins:

Os empresários preferiam o trabalho da mulher nas indústrias porque elas aceitavam salários inferiores aos dos homens, porém faziam os mesmos serviços que estes. Em razão disso, as mulheres sujeitavam-se a jornadas de 14 a 16 horas por dia, salários baixos,

\footnotetext{
${ }^{8}$ GONÇALVES, Carlos Roberto. Direito Civil Brasileiro: Parte Geral. 12a ed. São Paulo: Saraiva. 2014. p. 120.
} 
trabalhando em condições prejudiciais à saúde e cumprindo obrigações além das que lhes eram possíveis, só para não perder o emprego. ${ }^{9}$

O país pioneiro no avanço tecnológico foi o mesmo que percebeu a necessidade de proteção feminina no âmbito trabalhista era evidente em razão do abuso e a enorme disparidade sofrida. Dessa forma, a Inglaterra em 1842 pela manifestação conhecida como Coal Mining Act, anunciou a proibição da atividade de mulheres em minas e subterrâneos.

Esclarecendo em relação às manifestações legislativas:

As primeiras manifestações legislativas a respeito do trabalho da mulher surgiram na Inglaterra com o Coal Mining Act, de 1842, proibindo as mulheres em subterrâneos; no Factory Act, de 1844, limitando seu trabalho a doze horas, proibindo o período noturno[...]. ${ }^{10}$

No Brasil, acompanhando o pensamento de Maurício Godinho Delgado, a Lei Áurea de certa maneira foi o início da legislação trabalhista no país, divisa célebre que finda a escravidão e estimula o início do trabalho livre e assalariado. No entanto a Constituição da República de 1891, logo após a abolição, não previa questões sociais, mas somente a liberdade do trabalho e ainda não apresentava preocupação em regulamentar as relações empregatícias.

Ressaltando as ponderações acima de Godinho Delgado:

Embora a Lei Áurea não tenha, obviamente, qualquer caráter. Justrabalhista, ela pode ser tomada, em certo sentido, como o marco inicial de referência da História do Direito do Trabalho brasileiro. É que ela cumpriu papel relevante na reunião dos pressupostos a configuração desse novo ramo jurídico especializado. ${ }^{11}$

A primeira norma do país que cuidou da situação da mulher trabalhadora foi o decreto $\mathrm{n}^{\circ} 21.417$-A de 1932 que regulamentava o trabalho nos estabelecimentos industriais e comerciais, assegurando a segurança à

\footnotetext{
${ }^{9}$ MARTINS, Sérgio Pinto. Direito Do Trabalho. 28a . ed. São Paulo: Atlas, 2012, p. 615.

${ }^{10}$ BOSSA, Sônia. Direito Do Trabalho Da Mulher: No Contexto Social Brasileiro E Medidas Antidiscriminatórias. ${ }^{a}$.ed. São Paulo: Oliveira Mendes, 1998, p.5.

${ }^{11}$ DELGADO, Mauricio Godinho. Curso De Direito Do Trabalho. 15a ed. São Paulo: LTR, 2016, p, 110.
} 
maternidade por intermédio do descanso obrigatório de quatro semanas antes e após o parto, a vedação do trabalho noturno das 22 horas às 5 horas, entre outras disposições.

Outro marco importante foi o advento da CLT em 1943, inserindo de maneira definitiva os direitos e garantias dos cidadãos brasileiros na legislação e tolerando o trabalho noturno feminino de mulheres maiores de 18 anos e com algumas restrições. ${ }^{12}$

A respeito da criação da Consolidação das Leis do Trabalho:

O Governo resolveu, então, reunir os textos legais num só diploma, porém foi mais dalém de uma simples compilação porque, embora denominada Consolidação, a publicação acrescentou inovações aproximando-se de um verdadeiro Código. Não obstante, a matéria de previdência social e de acidentes do trabalho permaneceu separada em outras leis. Foram reunidas as leis sobre o direito individual do trabalho, direito coletivo do trabalho e direito processual do trabalho. ${ }^{13}$

Nos dias que correm, vigora a Constituição de 1988, retirou os direitos trabalhistas da parte econômica e social e as incluiu em direitos e garantias fundamentais, dando mais segurança aos trabalhadores. $\mathrm{O}$ artigo $5^{\circ}$ assegurou a igualdade de tratamento entre homens e mulheres, mostrando que as medidas de proteção feminina devem ser afastadas, para não gerar prejuízos às mesmas, apenas necessária com relação à maternidade. ${ }^{14}$

Em relação a garantir os direitos em relação à área trabalhista, é necessários ressaltar a OIT, ou seja, a Organização Internacional do Trabalho que é uma pessoa jurídica de direito público internacional, formada por vários países, que são designados de Estados-membros, atualmente por 187 países, sendo o Brasil integrante. Sua estrutura é constituída por três órgãos: Conselho de Administração, Repartição Internacional do Trabalho e a Conferência Internacional do Trabalho.

Complementando sobre os órgãos e suas funções:

\footnotetext{
12 JORGE NETO, Francisco Ferreira; CAVALCANTE, Jouberto de Quadros Pessoa. Direito Do Trabalho. 7. ed. São Paulo, Atlas, 2013.

${ }^{13}$ NASCIMENTO, Amauri Mascaro; FERRARI Irany; FILHO Ives Gandra da Silva Martins. História Do Trabalho, Do Direito Do Trabalho E Da Justiça Do Trabalho. $3^{\mathrm{a}}$. ed. São Paulo: LTR, 2011, p.147.

${ }^{14}$ BOSSA, Sônia. Direito Do Trabalho Da Mulher: No Contexto Social Brasileiro E Medidas Antidiscriminatórias. $1^{a}$.ed. São Paulo: Oliveira Mendes, 1998, p.9.
} 
A Conferência é órgão deliberativo e se reúne sempre que necessário em local designado pelo Conselho de Administração. O conselho de Administração exerce função executiva e é composto de representantes governamentais, de empregadores e de empregados. A Repartição Internacional do Trabalho é a secretaria permanente e centro de documentação, dedicando-se especialmente à divulgação de atividades da OIT e publicações das Convenções e Recomendações $[\ldots]^{15}$

A busca pela harmonização do direito do trabalho em âmbito universal efetivou a existência do chamado Código Internacional do Trabalho, uma compilação de leis, não literalmente um Código, motivo pelo qual nela incluem convenções e recomendações.

No Brasil, para que as disposições da OIT possuam validade no ordenamento jurídico interno, é indispensável que o Congresso Nacional discuta e aprove. Após a aprovação desse órgão constitucional, cabe ao Governo federal formalizar a ratificação depositando na RIT, dessa forma, ultimamente o Presidente da República expede o decreto de promulgação. ${ }^{16}$

Conforme previsto nas informações da OIT Brasil, internacionalmente possuem 12 convenções que estabelecem proteção à mulher e igualdade de gênero. No entanto o Brasil ratificou apenas metade delas que passaram a ter validade no país.

Acerca da relação entre OIT e o Trabalho Feminino:

Desde a sua fundação, a OIT realizou inúmeras conferências. A primeira Conferência Geral da OIT, que se celebrou em Washington em 1919, adotou normas internacionais sobre a proteção da maternidade e limitando o emprego noturno das mulheres para resguardar a sua saúde. ${ }^{17}$

Outrossim, as Convenções de maior enfoque são as de $\mathrm{n}^{\circ} 100$ que prevê igualdade de remuneração entre os sexos e a 111 que disciplina sobre a discriminação no âmbito trabalhista.

Esclarecendo sobre o que compreende por discriminação, qualquer:

\footnotetext{
${ }^{15}$ ROCHA, Sílvia Regina da. O Trabalho Da Mulher À Luz Da Constituição De 1988. $1^{\text {a }}$ ed. Rio de Janeiro: Forense, 1991, p.14

${ }^{16}$ MARTINS, Sérgio Pinto. Direito Do Trabalho. 28a . ed. São Paulo: Atlas, 2012, p. 76.

${ }^{17}$ ROCHA, Sílvia Regina da. O Trabalho Da Mulher À Luz Da Constituição De 1988. $1^{\text {a }}$ ed. Rio de Janeiro: Forense, 1991, p.17
} 
[...] distinção, exclusão ou preferência fundada em raça, cor, sexo, religião, opinião política, ascendência nacional, origem social ou outra distinção, exclusão ou preferência especificada pelo Estadomembro interessado, qualquer que seja sua origem jurídica ou prática e que tenha por fim anular ou alterar a igualdade de oportunidade ou de tratamento no emprego ou profissão. ${ }^{18}$

De tal forma, ambas as Convenções que resguardam o direito de igual remuneração da mulher foram elevadas na Constituição de 1988 em princípios fundamentais previstos no artigo $7^{\circ}, \mathrm{XXX}$.

Respaldando-se no pensamento de Martins "pode-se dizer que os critérios legais que proíbem discriminações são decorrentes da aplicação ampla do princípio da isonomia. "19, sendo previsto por orientação da Constituição a produção de legislação infraconstitucional, é também presente na CLT em seu artigo 461 que "Sendo idêntica a função, a todo trabalho de igual valor, prestado ao mesmo empregador, na mesma localidade, corresponderá igual salário, sem distinção de sexo, nacionalidade ou idade.".

Para melhor compreensão se faz imprescindível analisar as causas que tornam o desafio da igualdade de gênero tão "utópico" de ser alcançado. $\mathrm{O}$ que a sociedade em geral precisa entender que uma sociedade menos igualitária é pouco desenvolvida socialmente e isso reflete diretamente na economia do país.

\section{DESAFIOS E CAUSAS DA DIFERENÇA SALARIAL}

Mesmo a mulher ocupando grande papel no mercado de trabalho, persistem ainda grandes desafios e causas da desigualdade, englobando principalmente a dupla jornada de trabalho, licença maternidade com duração mínima de 120 dias atualmente paga pelo Poder Público, o auxílio creche para empresas com mais de 30 mulheres maiores de 16 anos, descansos especiais para a amamentação, entre outras circunstancias que dificultam a mulher no mercado de trabalho.

O trabalho doméstico antigamente era justificado como afazer das mulheres por não exercerem funções fora do lar, hoje em dia a realidade da mulher mudou e a ocupação feminina está presente em diversas

\footnotetext{
${ }^{18}$ OIT: artigo $1^{\circ}$ da Convenção ${ }^{\circ} 111$.

${ }^{19}$ MARTINS, Sérgio Pinto. Direito Do Trabalho. 28 . ed. São Paulo: Atlas, 2012, p. 507.
} 
profissões, mas a circunstância do trabalho de casa não acompanhou. Pela lógica, quando apenas os homens trabalhavam o serviço doméstico era feito exclusivamente pela mulher, atualmente, com ambos os conjugues inseridos no mercado de trabalho não deveria ser divido?

Nas palavras de Léa Calil:

\begin{abstract}
Se, antigamente, o espaço doméstico era o lugar privativo da mulher, e os afazeres domésticos, sua obrigação, com a saída da mulher para o mercado de trabalho isto nada ou pouco mudou: na esmagadora maioria dos lares, o espeço doméstico e seus afazeres continuam sendo obrigação da mulher. ${ }^{20}$
\end{abstract}

Infelizmente a sociedade prossegue tratando as mulheres tal como seres inferiores, que mesmo se esforçando para conciliar os desafios e buscando seu espaço fora de casa e continua arcando em sua grande maioria das vezes sozinha com a louça do jantar, cama bagunçada, roupa para lavar e etc.

De acordo com a Síntese de Indicadores Sociais (SIS) de 2016, a última concluída até o presente momento, o sexo feminino se mantem abarrotada com afazeres domésticos, gastando e dedicando o dobro do tempo do que os homens nos serviços de casa. A justificativa que em média as mulheres trabalham menos em seu trabalho principal não escusa os homens, não há evolução em 11 anos de a mulher brasileira trabalhar menos que os homens em modo geral.

Também, por muito tempo a gravidez foi utilizada como grande empecilho para que as mulheres não pudessem integrar o mercado de trabalho e ficassem a mercê da casa cuidando dos filhos. Com base na dupla revolução do século XIII, anteriormente abordadas, as necessidades da época foram bastantes para provar o contrário.

A respeito do embaraço encontrado nesse sentindo, Léa Calil:

e, principalmente após a revolução industrial, que promoveu o emprego de mulheres em larga escala, caíram por terra os argumentos de que a mulher não deveria trabalhar, surgindo a necessidade de garantir-lhes direitos iguais ao dos homens trabalhadores. Ainda hoje existem defensores de que a maternidade é um empecilho para a contratação de mulheres em idade reprodutiva; porém, vez que o

\footnotetext{
${ }^{20}$ CALIL, Léa Elisa Silingowschi. Direito Do Trabalho Da Mulher: A Questão Da Igualdade Jurídica Ante A Desigualdade Fática. 1ª . ed. São Paulo: LTR, 2007, p. 80.
} 
poder público arca integralmente com o pagamento do salário-maternidade, semelhante argumento mascara, na verdade, preconceito. ${ }^{21}$

Anteriormente a promulgação da Convenção $n^{\circ} 3$ da OIT em 1919, o empregador era pessoalmente responsável pelo pagamento do salário da mulher afastada, refletindo numa maior discriminação e dificuldade da mulher ingressar no mercado de trabalho. Concomitantemente com o advento da Convenção $n^{\circ} 3$ e a disposição nela presente, trazendo que "em caso algum o empregador deverá ficar pessoalmente responsável pelo custo das prestações devidas à mulher que emprega", o salário integral da licença maternidade passa a ser pago pelo poder público, acarretando em um incentivo para a contratação do trabalho feminino.

Outro grande desafio são as creches, dado que na grande parte das vezes somente o Poder Público não consegue atender toda demanda de creches e pré-escolas necessárias para população, fazendo com que a mãe trabalhadora abdique de seu ofício para cuidar do filho, constituindo mais um desafio para o trabalho igualitário da mulher. Surge isto posto regulamentação na CLT para entidades públicas dirigidas a educação atuarem em locais de maior necessidade.

Lamentavelmente, inexiste estímulo da administração pública para que as empresas mantenham creches ou locais próprios para o ensino de filhos de seus funcionários, sendo oferecido somente pelo Ministro do Trabalho um diploma de benemerência, sem grandes benefícios ou principalmente incentivos fiscais para os empresários.

Além do mais, existe o obstáculo da amamentação, diretamente ligado com a biologia feminina e essencial ao bebe o leite materno por ser o alimento mais complexo e equilibrado para o desenvolvimento, além de único mantimento nos seus primeiros 6 (seis) meses de vida.

No mesmo diapasão ensina Luciano Martinez:

Segundo a Organização Mundial de Saúde, as crianças devem receber aleitamento materno exclusivo até, no mínimo, os seis meses de idade, o que se confirma mediante a leitura do art. 396 da CLT. Este, portanto, deve ser o referencial aplicado para o preenchimento

\footnotetext{
${ }^{21}$ CALIL, Léa Elisa Silingowschi. Direito Do Trabalho Da Mulher: A questão da igualdade jurídica ante a desigualdade fática. $1^{\text {a }}$. ed. São Paulo: LTR, 2007, p. 58.
} 
do conceito de "período da amamentação", constante da legislação. ${ }^{22}$

A fim de garantir que a mulher volte a trabalhar após o término de sua licença maternidade, a CLT estabelece o direito da mulher que está em período de amamentação de seu até 6 (seis) meses de idade ter garantia a 2 descansos especiais, de meia hora cada um. A lei sabiamente não previu a constância dos intervalos, justamente pelo apetite do recém-nascido indispor de horário preciso.

Vólia Bomfin Cassar ressalta que:

O legislador propositadamente não informou a periodicidade do intervalo, apenas garantiu dois intervalos de 30 minutos, já que a fome do bebê não ocorre em horário exato, apesar de previsível (de três em três horas, em média). Provavelmente os intervalos recairão: um antes do intervalo para refeição e outro depois. [...] A alimentação da criança deve ocorrer em local apropriado. A regra foi dirigida às mães que laborem próximo ao local do trabalho e da creche ou às que trabalhem em empresas que mantêm creche, o que é raro. Nos dias atuais, é muito comum que, após a licença-maternidade, a mulher não tenha como estar com o bebê para alimentálo diretamente, já que o intervalo é exíguo para percorrer distâncias maiores. Por esse motivo, entendemos que a mulher que recolher o leite materno no local de trabalho, por bombas mecânicas ou elétricas, para posterior alimentação do bebê, também tem direito ao intervalo, no prazo e na forma prevista pela lei (interpretação histórico-evolutiva). ${ }^{23}$

Tratando-se apenas de empresas onde trabalharem no mínimo 30 (trinta) mulheres com idade superior a 16 (dezesseis) anos a lei exige local próprio para as funcionárias deixarem seus filhos no período de amamentação, ou seja, os primeiros 6 meses de vida do bebê. $\mathrm{O}$ ambiente para tornar-se adequado é imprescindível "um berçário, uma saleta de amamentação, uma cozinha dietética e uma instalação sanitária. " Essa é a única disposição que faz necessário tal auxilio presente no $\S 1^{\circ}$ do artigo 389 .

Nesse sentido complementa Sergio Pinto Martins:

Os estabelecimentos que tiverem pelo menos 30 mulheres com mais de 16 anos de idade terão local apropriado onde seja permitido

\footnotetext{
${ }^{22}$ MARTINEZ, Luciano. Curso De Direito Do Trabalho. 4a . ed. São Paulo: Saraiva, 2016, p. 1327.

${ }^{23}$ CASSAR, Vólia Bomfin. Direito Do Trabalho. 11a . ed. São Paulo: Método, 2016
} 
às empresas guardar sob vigilância seus filhos no período de amamentação. A referida exigência poderá ser suprida mediante creches distritais mantidas, diretamente ou mediante convênios, com outras entidades públicas ou privadas, pelas próprias empresas, em regime comunitário, ou a cargo do Sesi, do Sesc, da LBA ou de entidades sindicais. ${ }^{24}$

Em termos práticos, o horário destinado à amamentação apenas funciona em empresas em que, por força de lei, possuam locais para deixar os filhos ou para mães que residam bem próximas ao seu local de trabalho, podendo deslocar-se com facilidade e rapidez. Para a maioria das mulheres o desafio continua tornando obstáculo para prosseguir trabalhando normalmente após o exaurimento da licença maternidade.

Com a demonstração de alguns desafios e causas que refletem diretamente no salário e trabalho da mulher brasileiro, fica evidente que existem alguns motivos com relação direta com a biologia e fisiologia, as mulheres pela própria natureza possuem menos massa muscular, igualmente engravidam para a continuação da espécie humana, outra parcela das razões sãos mais sociais, tal como dedicar-se menos ao trabalho por ter filhos e casualmente necessitar leva-los ao médico, ou por acreditarem não ter o mesmo tempo disponível que o homem para exercer as funções contratadas.

O motivo mais preocupante encontrado e demonstrativo do preconceito ainda presente é de que o trabalho da mulher vale menos do que o homem, reflexo da dificuldade de mulheres ocuparem cargos de chefia ou serem promovidas.

A diminuição da desigualdade de gêneros constitui uma das pautas das "Metas do Milênio" estabelecidas pela ONU, nesse milênio a busca pela consciência e principalmente a educação das próximas gerações são importantes para as pretensões de respeito às diferenças e efetivação de todos os direitos estabelecidos.

\section{ANÁLISE DO PROJETO DE LEI 6.393/2009}

Embora a Lei Maior brasileira garanta em seu artigo $5^{\circ}$ a igualdade de gênero, tal isonomia não é verificada no mercado de trabalho atual.

\footnotetext{
${ }^{24}$ MARTINS, Sérgio Pinto. Direito do trabalho. 28a . ed. São Paulo: Atlas, 2012, p. 634.
} 
$\mathrm{Na}$ tentativa de garantir de fato a igualdade, o projeto $n^{\circ} 6.393 / 2009$ visa acrescentar o parágrafo $3^{\circ}$ ao art. 401 da Consolidação das Leis do Trabalho, a fim de estabelecer multa para combater a diferença de remuneração verificada entre homens e mulheres no Brasil. Assim, encontra-se aprovado na Câmara dos Deputados desde o final de 2011, e no momento aguarda por assentimento do Senado Federal com o número PLC 130/2011.

Caso aprovado, a redação do $\S 3^{\circ}$ art. 401 ficaria:

$\S 3^{\circ}$ Pela infração ao inciso III do art. 373-A, relativa à remuneração, será imposta ao empregador multa em favor da empregada correspondente a cinco vezes a diferença verificada em todo o período da contratação.

Apesar da iniciativa do ex Deputado Federal Marçal Filho, que nem mais ocupa a mesma função, o projeto continua aguardando apreciação no senado federal, e após anos, parece que as mulheres podem esperar mais uma vez para a efetivação de um direito já defasado.

Em discurso proferido no Dia Internacional da Mulher, a Deputada Carmen Zanotto defende a aprovação:

[...] é uma pauta que nos remete a 159 anos atrás, quando 130 mulheres morreram na luta por alguns direitos, mas elas também lutavam pelo direito que ainda estamos lutando hoje, especialmente pela equiparação salarial. Não estamos pedindo nada diferente, estamos pedindo equiparação salarial para quem exerce a mesma função. ${ }^{25}$

Relevante observar que o projeto visa à igualdade salarial entre gêneros na mesma função e dentro de uma mesma empresa. Assim, se ambos trabalhadores de diferentes sexos possuam o mesmo cargo e funções, não há motivos para que a mulher tenha uma remuneração inferior.

Para as grandes empresas a inserção de penalidade para a desigualdade verificada não é vantajoso, motivo pelo qual há tanta morosidade e impedimentos para a aprovação no Senado.

Nesse sentindo o Senador Paulo Paim, relator da proposta na Comissão de Direitos Humanos ressalta:

\footnotetext{
${ }^{25}$ ZANOTTO, Carmen. Projeto Garante Igualdade Salarial Entre Homens E Mulheres. Disponível em: http://www12.senado.leg.br/noticias/audios/2016/03/projeto-garante-igualdade-salarial-entre-homens-e-mulheres.
} 
Por que eles não querem votar? Porque ali diz, já está na Constituição, claro e diz que uma vez verificado isso, essa discriminação com a mulher, vai ter multa. Ai o setor do grande capital não deixa o projeto avançar, já mandaram esse projetinho até para Comissão de Infraestrutura, vão jogando para as outras Comissões. ${ }^{26}$

A insistência em não cumprir a igualdade de salários traz a necessidade de impor sanções que incidam diretamente no bolso do empregador. Atualmente os benefícios inerentes à mulher, tal como licença maternidade são pagos pelo Poder Público, não havendo motivos visíveis e compreensivos de que o trabalho feminino traga prejuízo financeiro ao patrão.

Preteritamente havia falsas tentativas de justificar a diferenciação:

\begin{abstract}
O trabalho da mulher, historicamente, sempre teve menor valor que o do homem, ou seja, às mulheres sempre foi pago um salário inferior àqueles pagos aos homens pelas mais diversas contingências: porque produziam menos no início da industrialização, porque trabalhavam na produção de bens de menor valor no mercado, porque trabalhavam em empregos que exigiam menor qualificação, porque tinham menor capacidade de se organizar em sindicato. ${ }^{27}$
\end{abstract}

No momento atual, nenhumas das situações ocorrem e o projeto de lei $6.393 / 2009$ prevê que a multa seja aplicada em casos de mesma função. Além disso, no país cerca de $61 \%$ dos brasileiros formados em universidades são do sexo feminino, não podendo assim alegar falta de formação ou menor qualificação. ${ }^{28}$

Não basta apenas punir aquele mesmo cargo descrito na carteira de trabalho ou contrato, visto que o empregador como forma de evadir-se da multa poderá contratar com ocupações diversas, deverá a Justiça verificar a real função e desempenho de ambos os funcionários de sexos diferentes.

\footnotetext{
${ }^{26}$ PAIM, Paulo. Projeto Garante Igualdade Salarial Entre Homens E Mulheres. Disponível em: http://www12.senado.leg.br/noticias/audios/2016/03/projeto-garante-igualdade-salarial-entre-homens-e-mulheres.

${ }^{27}$ CALIL, Léa Elisa Silingowschi. Direito Do Trabalho Da Mulher: A Questão Da Igualdade Jurídica Ante A Desigualdade Fática. 1ª . ed. São Paulo: LTR, 2007, p. 67.

${ }^{28}$ SOUZA, Alexandre Gaiofato. A Multa Ao Empregador Por Pagar Salário Menor À Mulher. Disponível em: https://espaco-vital.jusbrasil.com.br/noticias/2209550/a-multa-ao-empregador-por-pagar-salario-menor-a-mulher.
} 
Penalizar o empregador com 5 (cinco) vezes a diferença salarial verificada em razão de sexo pode ser uma das medidas eficazes para combater a desigualdade, no entanto, far-se-á necessário uma maior fiscalização, também é essencial um maior esforço do legislado a fim de impulsionar a paridade, visto que, por mais que a sociedade evolua em diversos aspectos a cultura patriarcal persiste.

Como forma de combate ao empregador capaz de ultrapassar princípios constitucionais em busca da aquisição monetária é viável implantar medidas que comprometa o bolso do patrão.

É certo que a igualdade não é conquistada apenas com a vigência da lei, tornando-se imprescindível a conscientização da população não apenas para a isonomia de gêneros, mas sim no que diz respeito ao tratamento de todos, no âmbito pessoal e profissional.

Algumas medidas como aplicar multas, restringir créditos, trazer as empresas de grande porte transparência em seus critérios de remuneração e obrigatoriedade de relatórios entre homens e mulheres que ocupam o mesmo cargo com os respectivos salários, com fiscalização são opções eficazes para o desenvolvimento da verdadeira paridade.

\section{$5 \quad$ CONCLUSÃO}

É nítido perceber que o trabalho feminino percorreu um grande caminho até os dias atuais, entretanto as mulheres continuam enfrentando diversas situações das quais refletem diretamente em um salário inferior.

A Constituição Federal consagrou em seu artigo $5^{\circ}$ a igualdade entre homens e mulheres e ainda em leis esparsas há outros dispositivos com a finalidade de garantir essa diferença, no entanto não são bastante para evitar a prática discriminatória.

Igualmente a Consolidação das Leis do Trabalho apresenta dispositivos protecionistas que devem ser esquecidos e afastados, devendo apenas ser observados os pertinentes a gravidez, por ser a maternidade algo natural da mulher que possui função fisiológica díspar a do homem necessita adequações e proteções diversas, levando em conta a limitação própria do sexo feminino. 
Sobre os desafios e causas da disparidade salarial, deve-se ressaltar que o ônus de constituir uma família e das obrigações que esta constituição traz deve ser igualmente distribuído, tal compartilhamento que não ocorre na atualidade, conforme demonstra a Síntese de Indicadores Sociais (SIS) de 2016.

Dessa forma as mulheres continuam sobrecarregadas com afazeres domésticos, conhecido como dupla jornada de trabalho, gastando e dedicando o dobro do tempo do que os homens, um dos grandes motivos que refletem diretamente na preferência pelo trabalho masculino.

O trabalho dignifica o homem e atualmente é tratado como condição para a realização pessoal do indivíduo, no entanto para ser digno deve atender os direitos constitucionais previsto na Lei Maior, dessa forma a mulher que exerce a mesma função que o homem e não tem seu trabalho remunerado devidamente tem ferida sua dignidade.

Ainda, é inegável à necessidade de uma legislação rígida e punitiva para o empregador com relação direta ao seu bolso, entanto para melhor conjugação e efetivação dos direitos trabalhistas femininos é importante conjugar com a conscientização da população para que compreendam e ainda levem para as futuras gerações pensamentos igualitários e menos patriarcais.

\section{REFERÊNCIAS BIBLIOGRÁFICAS}

BOSSA, Sônia. Direito Do Trabalho Da Mulher: No Contexto Social Brasileiro E Medidas Antidiscriminatórias. $1^{\text {a }}$.ed. São Paulo: Oliveira Mendes, 1998.

CALIL, Léa Elisa Silingowschi. Direito do trabalho da mulher. 28a . ed. São Paulo: Atlas, 2012.

CASSAR, Vólia Bomfim. Direito Do Trabalho. 33a. ed. Niterói: Impetus, 2009.

DELGADO, Mauricio Godinho. Curso De Direito Do Trabalho. 15ª ed. São Paulo: LTR, 2016.

GONÇALVES, Carlos Roberto. Direito Civil Brasileiro: Parte Geral. 12 ed. São Paulo: Saraiva. 2014.

JORGE NETO, Francisco Ferreira; CAVALCANTE, Jouberto de Quadros Pessoa. Direito Do Trabalho. 7. ed. São Paulo, Atlas, 2013.

MARTINEZ, Luciano. Curso De Direito Do Trabalho. 4ª ed. São Paulo: Saraiva,2016.

MARTINS, Sérgio Pinto. Direito Do Trabalho. 28a . ed. São Paulo: Atlas, 2012.

NASCIMENTO, Amauri Mascaro; FERRARI, Irany; FILHO, Ives Gandra da Silva Martins. História Do Trabalho, Do Direito Do Trabalho E Da Justiça Do Trabalho. 3ª. ed. São Paulo: LTR, 2011.

OIT: artigo $1^{\circ}$ da Convenção $n^{\circ} 111$. 
PAIM, Paulo. Projeto Garante Igualdade Salarial Entre Homens E Mulheres. Disponível em: http://www12.senado.leg.br/noticias/audios/2016/03/projeto-garante-igualdade-salarial-entre-homens-e-mulheres.

ROCHA, Sílvia Regina da. O Trabalho Da Mulher À Luz Da Constituição De 1988. $1^{\text {a }}$ ed. Rio de Janeiro: Forense, 1991.

SOUZA, Alexandre Gaiofato. A Multa Ao Empregador Por Pagar Salário Menor À Mulher. Disponível em: https://espaco-vital.jusbrasil.com.br/noticias/2209550/a-multa-ao-empregador-por-pagar-salario-menor-a-mulher.

SZMRECSÁNYI, Tamás; Lapa, José Roberto do Amaral. História Econômica Da Independência E Do Império. 2a . Ed. Revista. São Paulo: Hucitec.2002.

ZANOTTO, Carmen. Projeto Garante Igualdade Salarial Entre Homens E Mulheres. Disponível em: http://www12.senado.leg.br/noticias/audios/2016/03/projeto-garante-igualdade-salarial-entre-homens-e-mulheres. 